\title{
Effects of admixture in native and invasive populations of Lythrum salicaria
}

\author{
Jun Shi • Mirka Macel • Katja Tielbörger · Koen J. F. Verhoeven $\mathbb{D}$
}

Received: 7 March 2017 / Accepted: 13 March 2018/Published online: 21 March 2018

(C) The Author(s) 2018

\begin{abstract}
Intraspecific hybridization between diverged populations can enhance fitness via various genetic mechanisms. The benefits of such admixture have been proposed to be particularly relevant in biological invasions, when invasive populations originating from different source populations are found sympatrically. However, it remains poorly understood if admixture is an important contributor to plant invasive success and how admixture effects compare between invasive and native ranges. Here, we used experimental crosses in Lythrum salicaria, a species
\end{abstract}

Electronic supplementary material The online version of this article (https://doi.org/10.1007/s10530-018-1707-2) contains supplementary material, which is available to authorized users.

J. Shi $\cdot$ M. Macel $\cdot$ K. Tielbörger

Institute of Ecology and Evolution, Plant Ecology Group,

University of Tübingen, 72076 Tübingen, Germany

\section{J. Shi}

Ningbo Academy of Agricultural Sciences,

Ningbo 315040, China

M. Macel

Department of Plant Science, Radboud University

Nijmegen, P.O. Box 9010, 6500 NL Nijmegen,

Netherlands

K. J. F. Verhoeven ( $\square)$

Department of Terrestrial Ecology, Netherlands Institute of Ecology (NIOO-KNAW), Droevendaalsesteeg 10, 6708 PB Wageningen, Netherlands

e-mail: k.verhoeven@nioo.knaw.nl with well-established history of multiple introductions to Eastern North America, to quantify and compare admixture effects in native European and invasive North American populations. We observed heterosis in between-population crosses both in native and invasive ranges. However, invasive-range heterosis was restricted to crosses between two different Eastern and Western invasion fronts, whereas heterosis was absent in geographically distant crosses within a single large invasion front. Our results suggest that multiple introductions have led to already-admixed invasion fronts, such that experimental crosses do not further increase performance, but that contact between different invasion fronts further enhances fitness after admixture. Thus, intra-continental movement of invasive plants in their introduced range has the potential to boost invasiveness even in well-established and successfully spreading invasive species.

Keywords Admixture - Biological invasions · Heterosis · Inbreeding depression · Phenotypic plasticity $\cdot$ Purple loosestrife

\section{Introduction}

Biological invasions are a global problem and we still do not know why some introduced plants become invasive whereas others do not (Kolar and Lodge 
2001). Some widely studied and partially supported hypotheses emphasize the role of biotic interactions to explain increased vigor of invasive species, e.g. the enemy release hypothesis (ERH) and the evolution of increased competitive ability hypothesis (EICA) (Keane and Crawley 2002; Joshi and Vrieling 2005; Puliafico et al. 2008; Felker-Quinn et al. 2013). However, less attention has been paid to alternative evolutionary genetic processes such as the consequences of admixture (Ellstrand and Schierenbeck 2000; Verhoeven et al. 2011; Bock et al. 2015; van Kleunen et al. 2015). Admixture has potential enhancing effects for population success, for instance by increasing genetic variation, creating novel genotypes and masking effects of fixed deleterious recessive mutations leading to heterosis (Rieseberg et al. 2003; Seehausen 2004; Verhoeven et al. 2011; Rius and Darling 2014). One underlying reason for heterosis after admixture is that individual populations often suffer from some level of inbreeding depression (Angeloni et al. 2011), especially when populations are small. Inbreeding depression is in part caused by accumulation and expression of deleterious recessive mutations and leads to plant fitness decrease (Charlesworth and Willis 2009). Admixture between diverged populations can alleviate the negative effects of inbreeding depression by masking the effects of deleterious mutations that were fixed in individual populations, contributing to heterosis (Xiao et al. 1995). An alternative effect of admixture, observed in crosses between very distant populations, can be outbreeding depression, due to dilution of local adaptation and disruption of co-adapted gene complexes that have diverged over evolutionary time (Waser and Price 1989; Verhoeven et al. 2011).

In early invasions, population bottlenecks often cause loss of genetic variation. Continued inbreeding in small founder populations can speed up purging of deleterious mutations (Facon et al. 2011) but this may not always be efficient enough to eliminate the negative effects of inbreeding (Frankham et al. 2001), suggesting that masking of deleterious mutations by admixture is beneficial during early invasions. Thus, when invasive species are introduced via multiple introductions from different native source populations, these diverged populations can readily meet and admix in the invasive range (Dlugosch and Parker 2008; Facon et al. 2008; Verhoeven et al. 2011) and this admixture may cause strong heterosis and boost invasive plant fitness in the early invasive stages (Drake 2006). Although heterosis is a transient effect, it can substantially boost the chance for initial population establishment (Drake 2006). Furthermore, admixture might continue to promote invasiveness in established invaders when new genotypes are introduced from the native range (van Kleunen et al. 2015).

The benefits of admixture apply also to native range populations, although it has been argued that local adaptation in native range populations reduces the benefits of admixture due to dilution of locally adapted gene pools (Verhoeven et al. 2011). This presumably plays a smaller role in invasive populations that have not yet evolved strong local adaptation. Thus, the balance between the costs and benefits of population admixture plays out differently in native populations compared to early invaders, with stronger selection for admixture in early invaders because there is less cost associated with diluting locally adapted gene pools. When early invaders are introduced from multiple source populations, it can therefore be hypothesized that selection for admixture leads to admixed invasion fronts (Ellstrand and Schierenbeck 2006); whereas source populations from the native area maintain a higher degree of differentiation (Verhoeven et al. 2011). This prediction can be tested empirically by evaluating offspring performance from within and between-population crosses and comparing these between native and invasive populations. Despite much interest in the role of admixture and evolutionary change in invaders few such studies exist (e.g. Wolfe et al. 2007; Rius and Darling 2014; van Kleunen et al. 2015), and consequently our insight in the role of admixture in biological invasions remains limited.

Here, we use Lythrum salicaria (Purple loosestrife) as a model species to study the effects of admixture in invasions. L. salicaria is a perennial, wetland-associated herbaceous plant. Well-established populations can survive in dry habitat for many years (Blossey and Schroeder 1995), but usually L. salicaria occurs along rivers, lakes, or other wet habitats. L. salicaria's relatively wide tolerance to different water stress levels in the recruitment phase may be a potential factor for its wide spreading in North America during last 200 years (Keddy and Ellis 1985). In the 1800 s, L. salicaria was initially introduced from native European populations into the east coast of North America (Thompson et al. 1987). Multiple 
introductions occurred along the east coast and both historical and genetic evidence indicate that this led to admixture between different native source populations (Thompson et al. 1987; Houghton-Thompson et al. 2005; Chun et al. 2009). After the $1850 \mathrm{~s}$, L. salicaria was recognized as a potential horticultural and landscape plant. It may be in this way that the species was first introduced into the Great Lakes region (Midwest) and also into the Pacific Northwest were small and widely scattered populations have been present since the early twentieth century (Stuckey 1980; Edwards 2012). Explosive invasive westward spread occurred since the $1930 \mathrm{~s}$ from the east coast introduction areas, possibly involving further admixture between local Midwestern populations and Westward spreading populations (Edwards 2012). Likewise, inland spread also occurred from the Northwestern L. salicaria sites into e.g. Idaho, Utah, Wyoming and northern California (Edwards 2012).

To investigate the effects of experimental admixture, we used L. salicaria from nine native European populations and nine invasive North American populations. Within both ranges we performed experimental crosses within and between populations at different geographic distances and we evaluated F1 offspring under two environmental treatments, wet and drought soil conditions, because the expression of heterosis can be environment-dependent (Velasco et al. 1987). We tested the hypotheses that (1) in native populations, admixture increases $L$. salicaria performance with increasing parental distance; and (2) in the invasive range, experimental admixture does not lead to improved performance because mixing between multiple introductions has already resulted in admixed populations (Thompson et al. 1987; Houghton-Thompson et al. 2005; Chun et al. 2009); crosses among such admixed populations are not expected to result in further heterosis.

\section{Materials and methods}

\section{Study species}

Lythrum salicaria L. (Purple loosestrife; Lythraceae) is an erect, wetland herbaceous perennial (Thompson et al. 1987). It is self-incompatible and flowers are pollinated by long-tongued insects (Agren 1996). It is heterostylous and each plant produces one of three morph-specific patterns: long-, mid- or short-styled morph (Waites and Agren 2004). The trimorphic system in L. salicaria avoids self-pollination (Colautti et al. 2010a, b) as legitimate pollination requires the deposition on the stigma of pollen from anthers of equivalent height, which are found only between different flower style lengths (Oneil 1992; Eckert et al. 1996; Waites and Agren 2004). In the invasive range, multiple introductions to Eastern North America are thought to have given rise to an admixed invasion front (Houghton-Thompson et al. 2005; Chun et al. 2009) in which adaptive population differentiation has evolved along the front's northern edge in response to climatic factors (Colautti and Barrett 2013).

Plant materials and experimental crosses

Seeds of $L$. salicaria were collected from populations in two ranges, Europe and North America, between 2004 and 2012; several of the seed provenances used had been included also in previous $L$. salicaria studies (e.g. Chun et al. 2009; Moloney et al. 2009). Within each range, seeds were used from three geographically distant regions and within each region we used three populations (Table 1). Distances between regions were larger in the North American range than in the European range, and in North America distances between populations within a region were larger in western regions than in eastern regions (specifically, population distances within regions were $3-15 \mathrm{~km}$ in the European samples; 4-15 km in the New Jersey samples; $25-31 \mathrm{~km}$ in the Idaho samples; and $113-200 \mathrm{~km}$ in the Iowa samples). From previous work it is known that genetic variation and population differentiation are higher in Europe than in North America, and within North America are higher in eastern than in western regions (Chun et al. 2009). The differences in the spatial scale of our population sampling reflect these differences in genetic variation, with spatially broader sampling in regions with lower variation and/or differentiation to capture sufficient variation also in areas of reduced variation. Distances between populations in both native and invasive areas were larger than distances that are usually covered by natural honey bee pollinators (Beekman and Ratnieks 2000 and references therein) and also larger than typical Lythrum salicaria seed dispersal (mostly $<10 \mathrm{~m}$; Thompson et al. 1987). In October 2012, seeds from 12 to 15 mother plants per population were 
Table 1 Geographic locations of Lythrum salicaria populations used in this study

\begin{tabular}{|c|c|c|c|c|c|c|}
\hline Origin & Region & Population & Latitude & Longitude & $\begin{array}{l}\text { Mean annual temp. } \\
\left({ }^{\circ} \mathrm{C}\right)\end{array}$ & $\begin{array}{l}\text { Annual precipitation } \\
(\mathrm{mm})\end{array}$ \\
\hline \multicolumn{7}{|c|}{ Europe (native) } \\
\hline & \multirow[t]{3}{*}{ Tübingen } & Hagelloch $(\mathrm{TH})^{*}$ & $\mathrm{~N} 48^{\circ} 33^{\prime}$ & $\mathrm{E} 09^{\circ} 01^{\prime}$ & \multirow[t]{3}{*}{$11.0^{\mathrm{a}}$} & \multirow[t]{3}{*}{$592.6^{\mathrm{a}}$} \\
\hline & & Unterjesingen $(\mathrm{TU}) *$ & $\mathrm{~N} 48^{\circ} 31^{\prime}$ & $\mathrm{E} 08^{\circ} 59^{\prime}$ & & \\
\hline & & Reusten (TR)* & $\mathrm{N} 48^{\circ} 33^{\prime}$ & $\mathrm{E} 08^{\circ} 56^{\prime}$ & & \\
\hline & \multirow[t]{3}{*}{ Potsdam } & Geltow (PG) & $\mathrm{N} 52^{\circ} 22^{\prime}$ & $\mathrm{E} 12^{\circ} 57^{\prime}$ & \multirow[t]{3}{*}{$10.8^{\mathrm{a}}$} & \multirow[t]{3}{*}{$553.8^{\mathrm{a}}$} \\
\hline & & Ferch (PF) & $\mathrm{N} 52^{\circ} 20^{\prime}$ & $\mathrm{E} 12^{\circ} 55^{\prime}$ & & \\
\hline & & Golmer Luch (PL) & $\mathrm{N} 52^{\circ} 24^{\prime}$ & $\mathrm{E} 12^{\circ} 57^{\prime}$ & & \\
\hline & \multirow[t]{3}{*}{ Wageningen } & Ewijk (NE) & N5 $1^{\circ} 52^{\prime}$ & $\mathrm{E} 05^{\circ} 45^{\prime}$ & \multirow[t]{3}{*}{$11.3^{\mathrm{b}}$} & \multirow[t]{3}{*}{$1002.0^{\mathrm{c}}$} \\
\hline & & Nijmegen (NN) & $\mathrm{N} 51^{\circ} 51^{\prime}$ & $\mathrm{E} 05^{\circ} 53^{\prime}$ & & \\
\hline & & Wageningen (NW) & $\mathrm{N} 51^{\circ} 58^{\prime}$ & $\mathrm{E} 05^{\circ} 40^{\prime}$ & & \\
\hline \multicolumn{7}{|c|}{ North America (invasive) } \\
\hline & \multirow[t]{3}{*}{ Idaho } & Star Idaho (ISI) & $\mathrm{N} 43^{\circ} 42^{\prime}$ & $\mathrm{W} 116^{\circ} 29^{\prime}$ & \multirow[t]{3}{*}{$9.9^{\mathrm{d}}$} & \multirow[t]{3}{*}{$377.3^{\mathrm{d}}$} \\
\hline & & Middleton (IML) & $\mathrm{N} 43^{\circ} 25^{\prime}$ & $\mathrm{W} 116^{\circ} 22^{\prime}$ & & \\
\hline & & Boise River (IBR) & $\mathrm{N} 43^{\circ} 36^{\prime}$ & $\mathrm{W} 116^{\circ} 11^{\prime}$ & & \\
\hline & \multirow[t]{3}{*}{ Iowa } & Boone Folks (IABF)* & $\mathrm{N} 42^{\circ} 17^{\prime}$ & W93 $56^{\prime}$ & \multirow[t]{3}{*}{$9.34^{\mathrm{d}}$} & \multirow[t]{3}{*}{$929^{d}$} \\
\hline & & $\begin{array}{l}\text { Little South Storm Lake } \\
\text { (IALS)* }\end{array}$ & $\mathrm{N} 42^{\circ} 38^{\prime}$ & W95 $14^{\prime}$ & & \\
\hline & & Manly (IAMA)* & $\mathrm{N} 43^{\circ} 16^{\prime}$ & $\mathrm{W} 93^{\circ} 07^{\prime}$ & & \\
\hline & \multirow[t]{3}{*}{ New Jersey } & New Jersey Site 1 (NJS1) & $\mathrm{N} 40^{\circ} 59^{\prime}$ & $\mathrm{W} 74^{\circ} 44^{\prime}$ & \multirow[t]{3}{*}{$11.4^{\mathrm{d}}$} & \multirow[t]{3}{*}{$1218.2^{\mathrm{d}}$} \\
\hline & & New Jersey Site 3 (NJS3) & $\mathrm{N} 41^{\circ} 05^{\prime}$ & $\mathrm{W} 74^{\circ} 43^{\prime}$ & & \\
\hline & & New Jersey Site 4 (NJS4) & $\mathrm{N} 41^{\circ} 07^{\prime}$ & $\mathrm{W} 74^{\circ} 43^{\prime}$ & & \\
\hline
\end{tabular}

*Same populations as used in Chun et al. (2009)

ahttp://www.wetterkontor.de/ (2014-2015, temperature and precipitation of Potsdam and Tübingen (Stuttgart) regions)

bhttps://weerstatistieken.nl/ (2014-2015, temperature of Wageningen (De Bilt) region)

${ }^{\mathrm{c}} \mathrm{http}$ //historie.neerslagkaart.nl/ (2014-2015, precipitation of Wageningen region based on source KNMI)

${ }^{\mathrm{d}}$ https://www.currentresults.com/Weather/US/weather-averages-index.php

sown in petri-dishes with water in a greenhouse (NIOO-KNAW, Wageningen, Netherlands) with $16 \mathrm{~h}$ light, $8 \mathrm{~h}$ dark and a constant $20^{\circ} \mathrm{C}$. Two weeks later, one seedling per mother plant was transplanted into $1.5 \mathrm{~L}$ pots filled with steamed commercial potting soil. In total, 228 seedlings were planted in the same greenhouse as used for the germination with the same conditions. Around 50 days after transplantation, three types of pollinations were made: (1) between plants within a single population (intrapopulation crosses), (2) between plants from different populations in the same region (interpopulation crosses) and (3) between plants from different populations in different regions within a range (inter-region crosses). Crosses were made within the native and invasive ranges, but not between the two ranges. For each of the 18 populations, the $12-15$ plants grown per population were used both as seed parent and as pollen donor for all cross types. Due to incompatibility within the style morphs [tristylous mating system (Eckert et al. 1996)], not all seed parents could be used for all cross types. In each population, we designated six individuals as seed parents and each of these seed parents was used for all three cross types, receiving pollen from randomly selected and compatible pollen donors from the respective populations and regions. This design efficiently controls for differences between seed parents when evaluating the effects of cross type on offspring. Moreover, maternal effects do not influence long-term growth and phenology in L. salicaria populations (Montague et al. 2008). In some populations one or two of the six seed parents did not produce F1 seeds for 
all three cross types. In such cases, F1 seeds were added from other seed parents who contributed to only one or two cross types. In our study, populations were identified by the identity of the seed parent (not pollen donor). In April 2013, the seed capsules from each plant were harvested and stored at $4{ }^{\circ} \mathrm{C}$.

\section{Greenhouse experiment}

Potting soil was mixed with $20 \%$ pumice. $10 \mathrm{~cm} \times$ $10 \mathrm{~cm} \times 10 \mathrm{~cm}$ pots were filled with $650 \mathrm{~g}$ planting soil. Per pot, $10 \mathrm{~g}$ Osmocote slow-release fertilizer pellets were added (considered as a relatively high nutrient level; Bastlova et al. 2004). During the experiment, pots were placed individually in plastic containers to hold excess water. Greenhouse conditions were kept at $16 \mathrm{~h}$ light and $8 \mathrm{~h}$ dark with a $21^{\circ} \mathrm{C} /$ $16{ }^{\circ} \mathrm{C}$ temperature (day/night) during the experiment.

Seeds were germinated in petri-dishes. After 2 weeks, all germinated seedlings from each family and cross type were selected randomly and transplanted into the pots and placed on greenhouse benches. The experiment followed a replicated randomized block design. Each replicate block contained 108 plants: two origins (native/invasive) $\times$ three regions per origin $x$ three populations per region $\times$ three cross types $\times$ two soil treatments (drought/ wet) $\times 1$ replicate. Due to limited greenhouse space the experiment was performed in two successive time blocks: three of six replicate blocks were included in the first Time Block which started from 1th March 2014 to end of April; another three of six replicates were included in the second Time Block from 10th May 2014 to 10th July. Several seedlings (3.5\% of total) did not establish within 1 week after transplantation and were removed from the experiment. More than half of these were from the native Tübingen region. We observed that in this region seedling failure was not higher in intra-population crosses than in other cross types, suggesting that not inbreeding depression but an other, unknown, factor caused seedling failure. Drought treatment was applied by adding $300 \mathrm{~mL}$ water to each pot every 3 days; in the wet treatment, pots were maintained continuously in a shallow layer of water $(2 \mathrm{~cm}$ deep) during the entire experiment which simulated a normal, optimal growing environment (Keddy and Ellis 1985).

After 6 weeks of growth in the greenhouse, plants were harvested. Plant height was measured $(\mathrm{cm})$ from the surface of the soil to the shoot tip. The biggest leaf of each plant was selected visually and its width and length $(\mathrm{cm})$ were measured. A proxy of leaf area was calculated by multiplying the width and length of the biggest leaf. The diameter of the main stem ( $\mathrm{mm}$ ) was measured $2 \mathrm{~cm}$ above the soil surface. The number of side branches ( $>2 \mathrm{~cm}$ long) from the main stem was determined. Shoots and roots were harvested after thorough rinsing to remove soil from the roots and shoot and root dry weight were determined after oven drying for at least $72 \mathrm{~h}$ at $65^{\circ} \mathrm{C}$. In L. salicaria, vegetative size was previously shown to correlate linearly and positively with total dry biomass, vegetative dry biomass, and total fruit production (Colautti et al. 2010a, b), indicating that biomass can be used as a proxy for plant fitness.

\section{Statistical analysis}

Statistical analyses were conducted using SAS 9.2 (SAS Institute, Cary, NC). We used linear mixed models (PROC MIXED) to test effects of cross type, soil treatment, origin and all their 2- and 3-way interactions on plant traits (fixed effects). Because the experiment was divided over two time periods, we stratified the data by including time block and its interaction with soil treatment as additional fixed effects. The model accounted for random effects of replicate block (nested within time block), population (nested within origin) and the 2- and 3-way interactions of population with soil treatment and cross type. Because strong heteroscedasticity was observed associated with the soil treatments, we fitted unequalvariances mixed models that accounted for different variances for the two treatment levels. We fitted a priori contrasts to evaluate the effect of cross type within each combination of origin and soil treatment. A variant of this model was fitted including only within-population crosses to test for phenotypic plasticity differences (in response to the drought-wet treatment) between native and invasive plant populations.

Additionally, in order to single out the effects of admixture within and between different invasion fronts, we performed an additional analysis that separated the North American data into two parts: (1) dataset one excluded offspring from crosses involving an Idaho parent, and thus only included offspring from cross types involving New Jersey and/ 
or Iowa regions (the Midwest/Eastern invasion front); (2) dataset two only included offspring from crosses that involved at least one parent from Idaho (representing the Northwestern invasion front). A similar mixed model as described above was fitted to these two data sets, including cross type, soil treatment, the cross type * soil treatment interaction, time block and the time block $*$ soil treatment interaction as fixed effects, while accounting for random effects of replicate block (nested within time block), population and the population * soil treatment and population * cross type interactions.

\section{Results}

Origin and treatment effects on plant growth

Invasive plants had significantly higher shoot biomass, higher total plant biomass, and lower shoot/root biomass ratio than native plants (Fig. 1; Table 2). The dry soil treatment reduced shoot biomass, total plant biomass and shoot/root biomass ratio compared to wet soil conditions (Fig. 1; Table 2). Significant interactions between origin and soil treatment were found for shoot and total plant biomass (Table 2). We subsequently tested for differences in plasticity to soil wet-dry variation between native and invasive populations by including only within-population crosses in the analysis. These analyses confirmed stronger responses to the experimental soil treatments in invasive populations: plants from both ranges showed similar total plant biomass under drought conditions, but invasive plants benefitted much more than native plants did from optimal (wet) growing conditions (Fig. 2). Most of the other phenotypic traits also exhibited greater plastic responses to soil treatment in invasive plants than in the natives (Fig. S1; Table S1).

Cross type effects on plant performance

Cross type effects varied among the individual populations (Fig. S2) but significant overall effects of cross type were found on shoot biomass and total plant biomass, with heterosis increasing with distance between populations (Fig. 1; Table 2). The effect of cross type on biomass was significantly influenced by soil treatment (significant cross type * soil treatment interaction), but the cross type effect was not significantly different between the two origins (Table 2).In invasive populations, F1 offspring from inter-region crosses showed better plant performance than offspring from intrapopulation crosses, which was illustrated by higher shoot and total plant biomass in both the dry soil and wet soil treatments (Fig. 1a, b). In native populations, inter-region crossed offspring also showed better plant performance than intrapopulation crossed offspring with significantly higher shoot and total plant biomass in wet soil treatment, but not in dry soil condition (Fig. 1a, b). There was no significant effect of cross type on the shoot/root biomass ratio in either the invasive or the native populations under both soil treatments (Fig. 1c).

Cross type effects within and between different invasive routes

The effect of experimental crosses on plant performance was contingent on the different invasion fronts that have been documented for L. salicaria in North America.

When analyzing the North American plants including only east coast and Midwest populations (from the same North-eastern invasion route, thus excluding crosses involving Idaho populations that derived from the Western invasion route), the effect of cross type on plant biomass disappeared (Fig. 3a; Table 3). In contrast, and although no overall significant effect was observed across both soil treatments (Table 3), the a priori contrast analysis of the crosses that involved at least one parent from Idaho indicated a significantly higher total biomass in inter-region crosses compared to intrapopulation crosses under wet soil conditions (Fig. 3b). Combined with the results of the overall analysis including all crosses (Fig. 1b), this indicates that heterosis was observed in the invasive range in crosses between the Eastern/ Midwestern invasion fronts and the Western invasion front, but not in crosses within these two fronts.

\section{Discussion}

We predicted that experimental crosses between populations and regions express heterosis in the native range (because native-range populations are differentiated resulting in some inbreeding depression), but not in the invasive range (because multiple historical 

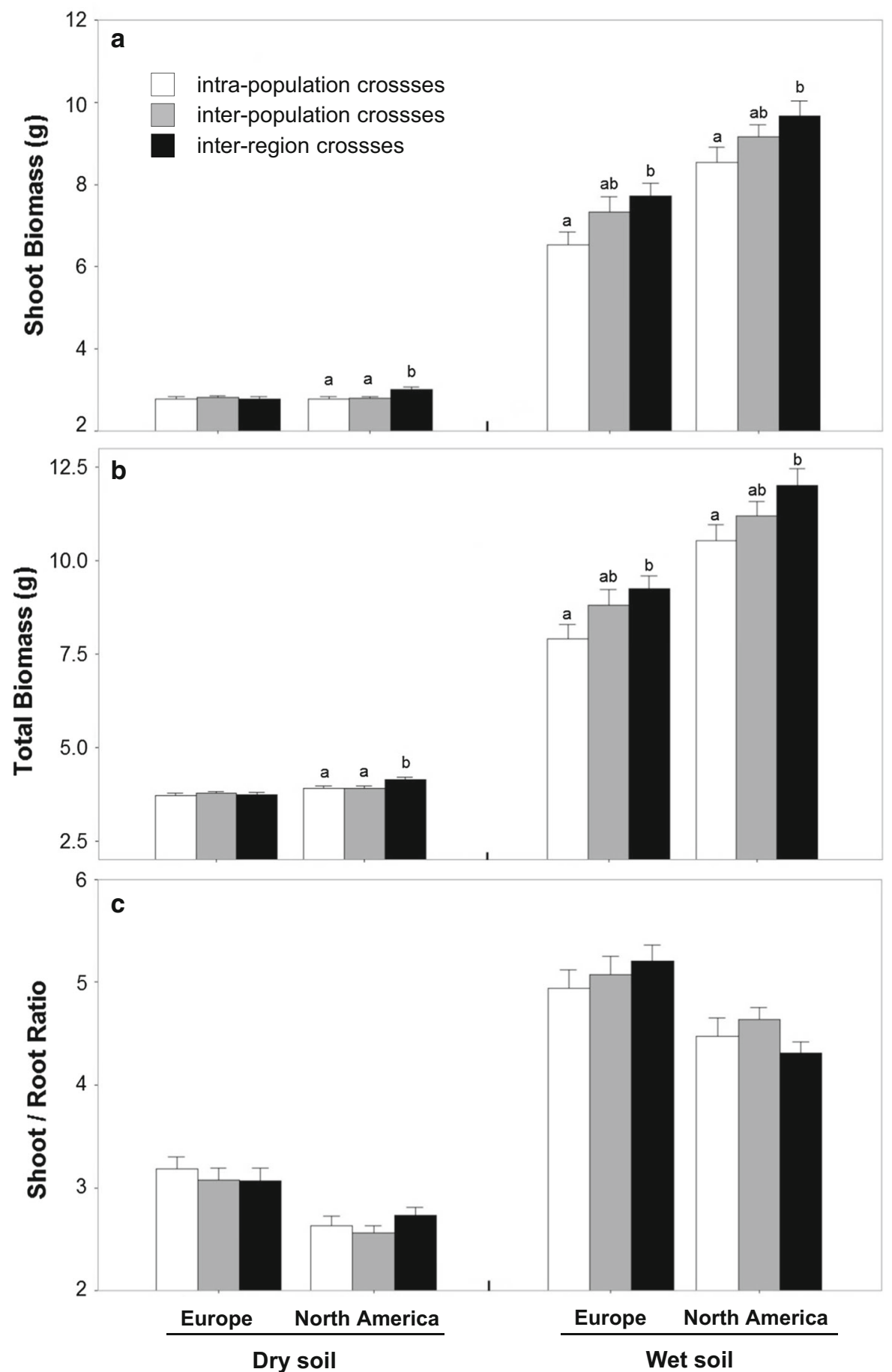

Fig. 1 Comparison of cross type effects in native (Europe) and invasive (North America) plants on shoot biomass, total plant biomass and shoot/root biomass ratio, as determined in F1 wet soil conditions and dry soil conditions. Statistical differences between cross types within each origin and soil treatment were assessed by linear contrasts and are indicated by different letters. The soil treatment effect was significant $(p<0.0001)$ for all three traits 
Table 2 Mixed model analysis results for shoot biomass, total plant biomass and shoot/root biomass ratio

\begin{tabular}{|c|c|c|c|c|}
\hline Variable & $d f$ & Shoot mass & Total mass & Shoot/root \\
\hline Origin & 1,16 & $55.57 * * *$ & $78.43 * * *$ & $25.22 * * *$ \\
\hline Cross type & 2,32 & $8.22 * *$ & $8.06^{* *}$ & 0.10 \\
\hline Soil treatment & 1,16 & $1787.38 * * *$ & $1649.75 * * *$ & $739.37 * * *$ \\
\hline Time block & 1,4 & $39.68 * *$ & $62.59 * *$ & 0.42 \\
\hline Cross type $\times$ origin & 2,32 & 0.15 & 0.26 & 0.36 \\
\hline Cross type $\times$ soil treatment & 2,32 & $5.72 * *$ & $5.76^{* *}$ & 0.95 \\
\hline Origin $\times$ soil treatment & 1,16 & $54.91 * * *$ & $62.40 * * *$ & 0.79 \\
\hline Cross type $\times$ origin $\times$ soil treatment & 2,32 & 0.12 & 0.02 & 2.31 \\
\hline Soil treatment $\times$ time block & 1,510 & $68.65 * * *$ & $74.08 * * *$ & 2.30 \\
\hline
\end{tabular}

The table presents $\mathrm{F}$ values and significance for fixed effects; see main text for random effects that are accounted for in the models. $p$ values that remain significant after false discovery rate correction for multiple testing (at table-wide FDR $=0.05$ ) are italicized Degrees of freedom $(d f)$ are specified for numerator and denominator respectively

${ }^{*} p<0.05 ; * * p<0.01$ and $* * * p<0.001$ respectively



Fig. 2 Effect of soil treatment on total plant biomass in native and invasive $L$. salicaria populations. Statistical testing used the same mixed model as described for Table 2, but using data from intra-population crosses only

introductions and selection for admixture has led to already-admixed invasion fronts). Contrary to prediction, our results showed heterosis in between-population crosses both in native and invasive populations of L. salicaria. However, heterosis in invasive plants was limited to crosses involving parents from two different Eastern and Western invasive routes. The species has a documented history of multiple introductions to Eastern North America with likely post-introduction admixture (Chun et al. 2009). We therefore propose that our result reflects an already-mixed Eastern/ Midwestern invasion front, in which experimental admixture does not provide an additional heterosis benefit anymore. Strikingly, such a heterosis effect is still possible when plants from different and invasion fronts mix. This highlights the potential of admixture to enhance invader fitness, also long after initial invader establishment. It also emphasizes the importance of efforts to avoid contact between different invasion fronts within an invaded continent in order to reduce the invasive success of exotic plants.

Even when our observed absence of heterosis in crosses within the Eastern/Midwestern invasion front suggest a lack of genetic differentiation between populations within this area, it is well known that invasive plant populations can rapidly evolve local adaptation to variation in environmental conditions in the new range (Bock et al. 2015). In fact, such adaptive differentiation has been demonstrated in L. salicaria populations in response to climatic factors along the northern edge of this Eastern/Midwestern invasion front (Colautti and Barrett 2013). Adaptive differentiation between populations may be less pronounced along the east-west cline of invasive spread, and if such adaptive differentiation occurred it was not reflected in heterosis effects in our crosses. Possibly, adaptive differentiation evolves more rapidly along latitudinal than longitudinal clines due to stronger climatic differences. 


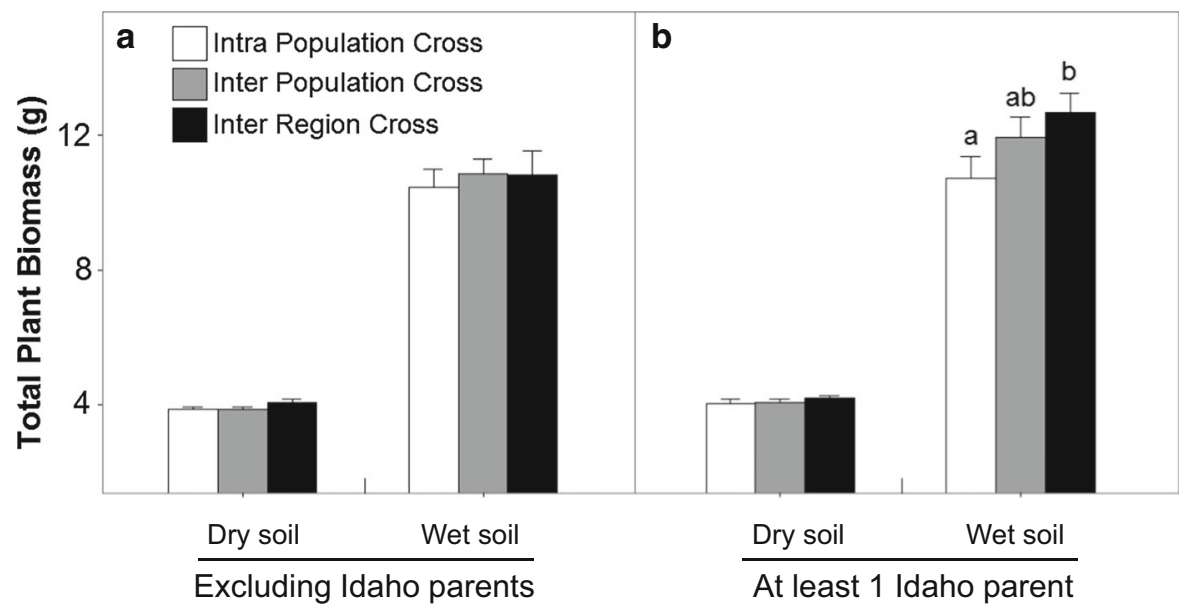

Fig. 3 Comparison of cross type effects on total plant biomass based on two different subsets of crosses that either include at least one parent from the Western invasion front ('Idaho') or that include only parents from the Eastern/Midwest invasion front ('No Idaho'), in dry and wet soil treatments. Statistical differences between cross types within each origin and soil treatment were assessed by linear contrasts and are indicated by different letters. The soil treatment effect was significant $(p<0.0001)$ in both data subsets

Table 3 Mixed model results for total plant biomass based on two different subsets of crosses that either include at least one parent from the Western invasion front ('Idaho') or that include only parents from the Eastern/Midwest invasion front ('No Idaho')

\begin{tabular}{|c|c|c|c|c|}
\hline \multirow[t]{2}{*}{ Variable } & \multicolumn{2}{|l|}{ Idaho } & \multicolumn{2}{|c|}{ No Idaho } \\
\hline & $d f$ & $\mathrm{~F}$ value & $d f$ & $\mathrm{~F}$ value \\
\hline Cross type & 2,4 & 3.65 & 2,10 & 0.84 \\
\hline Soil treatment & 1,8 & $578.06 * * *$ & 1,5 & $324.36^{* * *}$ \\
\hline Time block & 1,4 & $23.12 * *$ & 1,4 & $45.24 * *$ \\
\hline Soil treatment $\times$ cross type & 2,106 & 2.46 & 2,148 & 0.28 \\
\hline Soil treatment $\times$ time block & 1,106 & $31.82 * * *$ & 1,148 & $47.50 * * *$ \\
\hline
\end{tabular}

The table presents $\mathrm{F}$ values and significance for fixed effects; see main text for random effects that are accounted for in the models. $p$ values that remain significant after false discovery rate correction for multiple testing (at table-wide FDR $=0.05$ ) are italicized. Degrees of freedom $(d f)$ are specified for numerator and denominator respectively

${ }^{*} p<0.05, * * p<0.01$ and $* * * p<0.001$ respectively

In our study, invasive plants were larger than native plants. The bigger size of invasive L. salicaria is consistent with previous observations in this species (Blossey and Notzold 1995; Bastlova and Kvet 2002; Mal and Lovett-Doust 2005; Chun et al. 2009; Joshi and Tielborger 2012; Joshi et al. 2014) and for invasive species in general (Gallagher et al. 2015). Several non-exclusive hypotheses can explain this pattern. For instance, the EICA hypothesis predicts that invasive plants escape from natural enemies in their introduced range and subsequently evolve to allocate fewer resources to defenses and more to growth and reproduction (Blossey and Notzold 1995), and previous studies with similar populations has confirmed this hypothesis for Lythrum (Joshi et al. 2014). Admixture effects, such as demonstrated in our study, can be an additional contributor to increased vigor.

In native-range plants, admixture between different populations boosted plant performance with increased parental distances. This might reflect the effects of deleterious mutations that accumulated in natural populations due to local inbreeding. Molecular markers in a previous study illustrated a significant pattern 
of isolation by distance (between populations from Potsdam, Tübingen and Switzerland regions) in $L$. salicaria (Chun et al. 2009). Additionally, both the Tübingen and Wageningen population sizes are small ( $<500$ flowering individuals, pers. observations J. S. and K.J. F. V.). Small populations usually suffer more from inbreeding depression (Angeloni et al. 2011). The observed heterosis in experimental crosses between native populations may therefore be largely from lifting inbreeding depression (Charlesworth and Willis 2009). Outbreeding depression may also occur if the parental distance was large enough (Edmands 1999). However, we did not detect evidence for outbreeding depression the between native range populations, which were separated $\sim 600 \mathrm{~km}$ maximally.

Admixture may be more beneficial for invasive than for native populations, because invasive populations can benefit more from novel gene combinations in order to adapt to novel selection pressures (Ellstrand and Schierenbeck 2006) or because the negative effect of disrupting locally adapted genomes is less important in recent invaders (Verhoeven et al. 2011). Our results indicate that when the species is introduced to its invasive range through multiple introductions from different source populations, admixture is expected to lead to a fitness boost via heterosis. In invasive populations, we observed an admixture effect only in crosses between different western and an Eastern/ Midwestern invasion fronts. Over extensive geographic areas within the Eastern/Midwestern invasion front, experimental crosses showed little evidence of heterosis, despite well-documented multiple introductions. This is consistent with the idea that this large $L$. salicaria invasion front consists of already-admixed populations (Thompson et al. 1987; HoughtonThompson et al. 2005; Chun et al. 2009), such that further experimental admixture has little added effect on plant fitness. In North America, short-distance seed dispersal and pollen exchange are mainly driven by wind and insect pollination respectively (Grout et al. 1997; Thompson et al. 1987). Long-distance seed transport and/or seed spread occurred when seeds were embedded in mud adhering to wildlife, humans and vehicles, and trade as an ornamental plant (Mullin 1998; Mitich 1999; Stuckey 1980). These factors will promote admixture within the invasive Eastern/Midwestern front. However, our data showed that further heterosis was expressed after admixture between populations from different invasion fronts, when plants from these regions were crossed with invasive plants from a western US invasion route, suggesting the isolation between these two invasive fronts exists. Our results suggest that the further admixture between different invasion fronts may contribute to invasive success. However, in our study we only used one region in the western invasion front and it will be relevant to confirm the generality of our findings using multiple regions of both invasion fronts.

Our results suggest that admixture could contribute to plant performance in early invasion stages (as suggested by heterosis in inter-region crosses in native L. salicaria) but also much later in the process of invasive spread, as illustrated by heterosis in interregion crosses between different invasion fronts. However, effects of admixture for invasive success were not overwhelming, because F1 offspring from inter-region crosses of native $L$. salicaria were still smaller than offspring from intrapopulation crosses of invasive $L$. salicaria. Possibly additional factors have contributed to the evolution of vigorous invasive plants, for instance the evolution of increased competitive ability (EICA) after escaping from specialized natural enemies (Joshi et al. 2014).

Surprisingly, the effects of heterosis in L. salicaria were greater in optimal wet soil conditions than in more stressful drought conditions. However, most previous studies showed that inbred individuals are often more sensitive to environmental stress than outbred individuals (Fox and Reed 2011). This would predict more beneficial admixture effects under stressful conditions. However, our results may indicate that inbreeding depression sometimes is expressed more strongly in beneficial environments. Alternatively, it is possible that heterosis in our study was not associated with the lifting of inbreeding depression due to deleterious recessive mutations but with other mechanisms, such as the environmentdependent expression of overdominance or epistasis (Fethi et al. 2011).

In our study, we observed that L. salicaria from both native and invasive ranges showed similar total biomass under drought conditions, but invasive plants benefitted more than native plants did from wet (optimal) growing conditions. This difference in phenotypic plasticity between native and invasive populations suggests a 'master of some' strategy of the invasive plants (Richards et al. 2006), where invasive 
success is determined more by the capacity for rapid opportunistic growth when conditions are favorable than by the capacity to maintain fitness under a range of harsh conditions. This result is consistent with observations in other species (Davidson et al. 2011). A previous study also showed that invasive $L$. salicaria has phenotypic plasticity in both vegetative and reproductive traits (Mal and Lovett-Doust 2005). At high nutrient levels (as in our study), both shoot and root biomass exhibited greater phenotypic plasticity to increased water levels in invasive $L$. salicaria compared to native genotypes (Chun et al. 2007). Thus, our results supported previous findings of higher plasticity in invasive $L$. salicaria. In general, phenotypic plasticity is seen as an important contributor in colonization in environmentally diverse areas and plays a role in invasions (Williams et al. 1995; Kaufman and Smouse 2001; Maron et al. 2004).

In conclusion, our finding of clear heterosis effects after experimental crosses between native range populations but not between invasive range populations from a single large invasion front, despite welldocumented multiple introductions, is consistent with the idea that the invasion front consists of already well-admixed populations. Admixed invasion fronts are predicted to arise given the enhancing effects of heterosis and other admixture advantages for invasive spread. Strikingly, however, our finding of clear heterosis in crosses between different invasion fronts shows that further boosts to invasiveness in this wellestablished invader are expected when different invasion fronts meet. To minimize the ecological and economic impact of plant invasions, this emphasizes that it is important to think about avoiding not only new introductions from the native range, but also to avoid movement of propagules within the invasive range in order to prevent admixture between populations from different invasion fronts.

\section{Data, code and materials}

Data and statistical analysis code that are used in this article can be accessed at the Dryad digital repository: https://doi.org/10.5061/dryad.tr69js8.

Acknowledgements We like to thank Meta Schönau and Mark Stahl for facilitating the plant crossing and growing effort at the Tübingen greenhouses, and Carla Oplaat and Minggang
Wang for assistance in the execution of the experiment. We also like to thank Justin Fulkerson, Kirk Moloney, Claus Holzapfel, Lorenz Henneberg, Jasmin Joshi and Jörg Müller for collecting seeds.

Authors' contribution JS carried out the experimental crosses and the greenhouse experiment, and drafted the manuscript; KJFV carried out the statistical analyses; MM and KJFV conceived of and designed the study and contributed to writing the manuscript. KT contributed to data interpretation and manuscript writing. All authors gave final approval for publication.

Funding This work was funded by a Grant from the China Scholarship Council (CSC file No. 201206140020). KJFV was supported by a NWO-VIDI Grant (No. 864.10.008) from the Netherlands Organisation for Scientific Research. MM was supported by a DFG-SPP No. 1529 Grant from the Deutsche Forschungsgemeinschaft.

\section{Compliance with ethical standards}

Conflict of interest The authors declare that they have no conflict of interest.

Open Access This article is distributed under the terms of the Creative Commons Attribution 4.0 International License (http:// creativecommons.org/licenses/by/4.0/), which permits unrestricted use, distribution, and reproduction in any medium, provided you give appropriate credit to the original author(s) and the source, provide a link to the Creative Commons license, and indicate if changes were made.

\section{References}

Agren J (1996) Population size, pollinator limitation, and seed set in the self-incompatible herb Lythrum salicaria. Ecology 77:1779-1790

Angeloni F, Ouborg NJ, Leimu R (2011) Meta-analysis on the association of population size and life history with inbreeding depression in plants. Biol Conserv 144:35-43

Bastlova D, Kvet J (2002) Differences in dry weight partitioning and flowering phenology between native and non-native plants of purple loosestrife (Lythrum salicaria L.). Flora 197:332-340

Bastlova D, Cizkova H, Bastl M (2004) Growth of Lythrum salicaria and Phragmites australis plants originating from a wide geographical area: response to nutrient and water supply. Glob Ecol Biogeogr 13(3):259-271

Beekman M, Ratnieks FLW (2000) Long-range foraging by the honey-bee, Apis mellifera L. Funct Ecol 14:490-496

Blossey B, Notzold R (1995) Evolution of increased competitive ability in invasive nonindigenous plants-a hypothesis. J Ecol 83:887-889

Blossey B, Schroeder D (1995) Host specificity of three potential biological weed control agents attacking flowers 
and seeds of Lythrum salicaria (Purple loosestrife). Biol Control 5:47-53

Bock DG, Caseys C, Cousens RD, Hahn MA, Heredia SM, Hübner $S$ et al (2015) What we still don't know about invasion genetics. Mol Ecol 24:2277-2297

Charlesworth D, Willis JH (2009) Fundamental concepts in genetics. The genetics of inbreeding depression. Nat Rev Genet 10:783-796

Chun YJ, Collyer ML, Moloney KA, Nason JD (2007) Phenotypic plasticity of native vs. invasive purple loosestrife: a two-state multivariate approach. Ecology 88:1499-1512

Chun YJ, Nason JD, Moloney KA (2009) Comparison of quantitative and molecular genetic variation of native vs. invasive populations of purple loosestrife (Lythrum salicaria L., Lythraceae). Mol Ecol 18:3020-3035

Colautti RI, Barrett SCH (2013) Rapid adaptation to climate facilitates range expansion of an invasive plant. Science 342:364-366

Colautti RI, Eckert CG, Barrett SCH (2010a) Evolutionary constraints on adaptive evolution during range expansion in an invasive plant. Proc R Soc B 277(1689):1799-1806

Colautti RI, White NA, Barrett SCH (2010b) Variation of selfincompatibility within invasive populations of Purple loosestrife (Lythrum Salicaria L.) from Eastern North America. Int J Plant Sci 171:158-166

Davidson AM, Jennions M, Nicotra AB (2011) Do invasive species show higher phenotypic plasticity than native species and if so, is it adaptive? A meta-analysis. Ecol Lett 14:419-431

Dlugosch KM, Parker IM (2008) Founding events in species invasions: genetic variation, adaptive evolution, and the role of multiple introductions. Mol Ecol 17:431-449

Drake JM (2006) Heterosis, the catapult effect and establishment success of a colonizing bird. Biol Lett 2:304-307

Eckert CG, Manicacci D, Barrett SCH (1996) Frequency-dependent selection on morph ratios in tristylous Lythrum salicaria (Lythraceae). Heredity 77:581-588

Edmands S (1999) Heterosis and outbreeding depression in interpopulation crosses spanning a wide range of divergence. Evolution 53:1757-1768

Edwards KR (2012) Lythrum salicaria L. (purple loosestrife). In: Francis RA (ed) A handbook of global freshwater invasive species. Earthscan, New York, pp 91-102

Ellstrand NC, Schierenbeck KA (2000) Hybridization as a stimulus for the evolution of invasiveness in plants? Proc Natl Acad Sci USA 97:7043-7050

Ellstrand NC, Schierenbeck KA (2006) Hybridization as a stimulus for the evolution of invasiveness in plants? Euphytica 148:35-46

Facon B, Pointier JP, Jarne P, Sarda V, David P (2008) High genetic variance in life-history strategies within invasive populations by way of multiple introductions. Curr Biol 18:363-367

Facon B, Hufbauer RA, Tayeh A, Loiseau A, Lombaert E, Vitalis R et al (2011) Inbreeding depression is purged in the invasive insect Harmonia axyridis. Curr Biol 21:424-427

Felker-Quinn E, Schweitzer JA, Bailey JK (2013) Meta-analysis reveals evolution in invasive plant species but little support for Evolution of Increased Competitive Ability (EICA). Ecol Evol 3:739-751
Fethi B, Hanbary C, Mohamed E (2011) Genetic adaptability of inheritance of resistance to biotic and abiotic stress level on crop: role of epistasis. Afr J Biotechnol 10:19913-19917

Fox CW, Reed DH (2011) Inbreeding depression increases with environmental stress: an experimental study and metaanalysis. Evolution 65:246-258

Frankham R, Gilligan DM, Morris D, Briscoe DA (2001) Inbreeding and extinction: effects of purging. Conserv Genet 2:279-285

Gallagher RV, Randall RP, Leishman MR (2015) Trait differences between naturalized and invasive plant species independent of residence time and phylogeny. Conserv Biol 29:360-369

Grout JA, Levings CD, Richardson JS (1997) Decomposition rates of purple loosestrife (Lythrum salicaria) and Lyngbyei's sedge (Carex lyngbyei) in the Fraser River estuary. Estuaries 20(1):96-102

Houghton-Thompson J, Prince HH, Smith JJ, Hancock JF (2005) Evidence of hybridization between Lythrum salicaria (Purple loosestrife) and L-alatum (winged loosestrife) in North America. Ann Bot Lond 96:877-885

Joshi J, Vrieling K (2005) The enemy release and EICA hypothesis revisited: incorporating the fundamental difference between specialist and generalist herbivores. Ecol Lett 8:704-714

Joshi S, Tielborger K (2012) Response to enemies in the invasive plant Lythrum salicaria is genetically determined. Ann Bot Lond 110:1403-1410

Joshi S, Gruntman M, Bilton M, Seifan M, Tielborger K (2014) A comprehensive test of evolutionarily increased competitive ability in a highly invasive plant species. Ann Bot Lond 114:1761-1768

Kaufman SR, Smouse PE (2001) Comparing indigenous and introduced populations of Melaleuca quinquenervia (Cav.) Blake: response of seedlings to water and $\mathrm{pH}$ levels. Oecologia 127:487-494

Keane RM, Crawley MJ (2002) Exotic plant invasions and the enemy release hypothesis. Trends Ecol Evol 17:164-170

Keddy PA, Ellis TH (1985) Seedling recruitment of 11 wetland plant species along a water level gradient: shared or distinct responses? Can J Bot 63(10):1876-1879

Kolar CS, Lodge DM (2001) Progress in invasion biology: predicting invaders. Trends Ecol Evol 16:199-204

Mal TK, Lovett-Doust J (2005) Phenotypic plasticity in vegetative and reproductive traits in an invasive weed, Lythrum salicaria (Lythraceae) in response to soil moisture. Am J Bot 92:819-825

Maron JL, Vila M, Bommarco R, Elmendorf S, Beardsley P (2004) Rapid evolution of an invasive plant. Ecol Monogr 74:261-280

Mitich WL (1999) Purple loosestrife, Lythrum salicaria L. Weed Technol 13:843-846

Moloney KA, Knaus F, Dietz H (2009) Evidence for a shift in life-history strategy during the secondary phase of a plant invasion. Biol Invasions 11:625-634

Montague JL, Barrett SCH, Eckert CG (2008) Re-establishment of clinal variation in flowering time among introduced populations of purple loosestrife (Lythrum salicaria, Lythraceae). J Evol Biol 1(21):234-245

Mullin BG (1998) The biology and management of purple loosestrife (Lythrum salicaria). Weed Technol 12:397-401 
Oneil P (1992) Variation in male and female reproductive success among floral morphs in the tristylous plant Lythrum salicaria (Lythraceae). Am J Bot 79:1024-1030

Puliafico KP, Schwarzlnder M, Harmon BL, Hinz HL (2008) Effect of generalist insect herbivores on introduced $\mathrm{Le}$ pidium draba (Brassicaceae): implications for the enemy release hypothesis. J Appl Entomol 132:519-529

Richards CL, Bossdorf O, Muth NZ, Gurevitch J, Pigliucci M (2006) Jack of all trades, master of some? On the role of phenotypic plasticity in plant invasions. Ecol Lett 9:981-993

Rieseberg LH, Raymond O, Rosenthal DM, Lai Z, Livingstone $K$, Nakazato T et al (2003) Major ecological transitions in wild sunflowers facilitated by hybridization. Science 301:1211-1216

Rius M, Darling JA (2014) How important is intraspecific genetic admixture to the success of colonising populations? Trends Ecol Evol 29:233-242

Seehausen O (2004) Hybridization and adaptive radiation. Trends Ecol Evol 19:198-207

Stuckey RL (1980) Distributional History of Lythrum salicaria (Purple loosestrife) in North America. Bartonia J Phila Bot Club 47:3-20

Thompson DQ, Stuckey RL, Thompson EB (1987) Spread impact and control of purple loosestrife (Lythrum salicaria) in North Mmerican wetlands. Fish and Wildlife Research 1987 No.2, United States Department of the Interior Fish and Wildlife Service, Washington, DC van Kleunen M, Rockle M, Stift M (2015) Admixture between native and invasive populations may increase invasiveness of Mimulus guttatus. Proc R Soc B Biol Sci. https://doi.org/ 10.1098/rspb.2015.1487

Velasco T, Toro MA, Fuentes MC (1987) Heterosis and genotype-environment interaction-an experimental-study with Tribolium-castaneum. J Anim Breed Genet 104:273-282

Verhoeven KJF, Macel M, Wolfe LM, Biere A (2011) Population admixture, biological invasions and the balance between local adaptation and inbreeding depression. Proc R Soc B Biol Sci 278:2-8

Waites AR, Agren J (2004) Pollinator visitation, stigmatic pollen loads and among-population variation in seed set in Lythrum salicaria. J Ecol 92:512-526

Waser NM, Price MV (1989) Optimal outcrossing in IpomopsisAggregata-seed set and offspring fitness. Evolution 43:1097-1109

Williams DG, Mack RN, Black RA (1995) Ecophysiology of introduced Pennisetum-Setaceum on Hawaii-the role of phenotypic plasticity. Ecology 76:1569-1580

Wolfe LM, Blair AC, Penna BM (2007) Does intraspecific hybridization contribute to the evolution of invasiveness? An experimental test. Biol Invasions 9:515-521

Xiao JH, Li JM, Yuan LP, Tanksley SD (1995) Dominance is the major genetic-basis of heterosis in rice as revealed by Qtl analysis using molecular markers. Genetics 140:745-754 